Article

\title{
Enhancement of Spontaneous Polarization and Acid Vapor-Induced Polymerization in the Thin-Film States of Phenylterthiophene Derivative Bearing a Cyclotetrasiloxane Ring
}

\author{
Jumpei Nakagawa ${ }^{1}$, Atsushi Seki ${ }^{1,+} \mathbb{D}$ and Masahiro Funahashi ${ }^{1,2, *(\mathbb{D})}$ \\ 1 Program in Advanced Materials Science, Faculty of Engineering and Design, Kagawa University, \\ 2217-20 Hayashi-cho, Takamatsu, Kagawa 761-0396, Japan; s16g565@stu.kagawa-u.ac.jp (J.N.); \\ a_seki_3@rs.tus.ac.jp (A.S.) \\ 2 Health Research Institute, National Institute of Advanced Industrial Science and Technology, \\ 2217-14 Hayashi-cho, Takamatsu, Kagawa 761-0395, Japan \\ * Correspondence: funahashi.masahiro@kagawa-u.ac.jp; Tel./Fax: +81-87-864-2411 \\ + Present address: Department of Chemistry, Faculty of Science Division II, Tokyo University of Science, \\ 1-3 Kagurazaka, Shinjuku-ku, Tokyo 162-8601, Japan.
}

Received: 9 September 2020; Accepted: 28 October 2020; Published: 30 October 2020

check for updates

\begin{abstract}
We have achieved the measurement of spontaneous polarization of spin-coated thin films of a ferroelectric liquid crystal based on a phenylterthiophene skeleton. Uniaxially aligned spin-coated films with a thickness of $100 \mathrm{~nm}$ were prepared by the friction transfer method. The spontaneous polarization of the spin-coated films was measured by the Sawyer-Tower method and polarization inversion current technique under the application of triangular-wave bias. These measurements revealed the spontaneous polarization of $50 \mathrm{nC} \mathrm{cm}^{-2}$ in the thin-film state which is 1.5 times larger than the value of $35 \mathrm{nC} \mathrm{cm}^{-2}$ in the bulk state. This result should be attributed to the strong anchoring of the liquid-crystalline molecules on the substrate surface and the inhibition of polarization relaxation caused by the formation of the helical structure. Moreover, insolubilization of the thin films was carried out by an in situ ring-opening polymerization induced by acid vapors. The molecular alignment in the thin films of the ferroelectric liquid crystal was retained during the polymerization process.
\end{abstract}

Keywords: liquid-crystalline semiconductor; ferroelectric liquid crystal; spontaneous polarization

\section{Introduction}

Ferroelectric liquid crystals (FLCs) can be regarded as materials which are responsive to electric fields. FLCs have been extensively studied for the development of high-speed liquid crystal (LC) displays [1]. The strong interaction between the spontaneous polarization and the external electric field results in a short response time in the order of $1 \mu \mathrm{s}$, and the memory effect leads to low electrical power consumption [1]. For the display application, FLCs are used as fluidic materials pinched between two glass substrates and the thickness of the FLC materials is usually more than $2 \mu \mathrm{m}$ which is limited by the flatness of the substrates. Thus, optical and electrical properties of FLCs have been characterized in LC cells consisting of two glass plates coated with indium tin oxide (ITO), whose thickness is generally more than $2 \mu \mathrm{m}$ [2-4]. Studies on optical and physical properties of FLCs in thin-film states with thicknesses less than $1 \mu \mathrm{m}$ have been very limited.

The significance of preparation of LC thin films has been recognized for the applications of LC semiconductors comprised of extended $\pi$-conjugated units to thin-film electronic devices [5]. For applications to field-effect transistors and light-emitting diodes, the thickness of the LC thin films 
was less than $100 \mathrm{~nm}$ [6-8]. For FLCs bearing extended $\pi$-conjugated moieties, a few research groups have recently reported interesting phenomena based on the coupling of electronic charge transport with spontaneous polarization. The diodes with switchable polarity based on pyrene derivatives bearing hydrogen-bonding amide moieties [9], photorefractive effects of chiral terthiophene-based dye-doped LCs [10], linearly polarized electroluminescence with a rotatable polarized plane [11], and photovoltaic effects based on the built-in potential produced by spontaneous polarization instead of a $p$ - $n$ junction have been reported [12-16]. In the application of FLCs to diodes and photovoltaic devices as well as memories [17] and actuators [18], the preparation of thin films is essential. However, it has been difficult to produce thin films for FLCs with a thickness less than $1 \mu \mathrm{m}$ by a solution process.

Most FLCs are low-molecular weight materials and crystallize at room temperature. By the spin-coating method, polycrystalline inhomogeneous films with a high defect density are produced. Except for polymers bearing ferroelectric mesogens in their side chains $[19,20]$, spin-coated thin films of low-molecular weight FLCs have been quite limited and their polarization inversion currents or hysteresis loops characteristic of the ferroelectricity have not been confirmed in the thin-film states of FLCs.

Regarding external stimuli other than electric fields, a few research groups have provided acid vapor-responsive organic liquids which change their colors by the reaction between the basic compounds with acid vapors [21]. We have already reported LC perylene bisimide derivatives bearing cyclotetrasiloxane rings which polymerize in thin-film states by exposure to acid vapors [22]. The stabilization and insolubilization of thin films are necessary for device fabrication. Only a few photopolymerizable FLCs have been reported; however, other in situ polymerization methods have been limited [23].

In this study, we synthesized an FLC consisting of a phenylterthiophene unit and a cyclotetrasiloxane ring. FLC thin films with a thickness around $100 \mathrm{~nm}$ were deposited on glass substrates coated with ITO by a spin-coating method. The aluminum (Al) electrode was vacuum-deposited on the LC layer to prepare a sandwich-type sample. The spontaneous polarization of the thin films was determined by polarization inversion current measurements and the Sawyer-Tower method. These measurements revealed that the spontaneous polarization in the thin-film state was 1.5 times larger than that in the bulk state. In addition, the insolubilization of the thin films was carried out by an in situ ring-opening polymerization induced by acid vapors. The molecular alignment in the as-deposited LC thin films was retained during the polymerization process.

\section{Materials and Methods}

\subsection{Synthesis and Mesomorphic Behaviors of FLCs}

In general, it is not always easy to produce homogeneous thin films of LC compounds by the spin-coating method. Most LC materials crystallize at room temperature and inhomogeneous crystallization occurs during the solvent evaporation in the spin-coating process [24]. We have studied the preparation of the thin films of LC semiconductors by the spin-coating method [25-28]. When we use LC semiconductors which exhibit ordered smectic phases or columnar phases at room temperature, homogeneous thin films of the LC states can be produced by the spin-coating method at room temperature. From the self-healing effect in the LC phases, homogeneous thin films with low defect densities could be obtained by a thermal annealing. High-quality LC thin films were applied to field-effect transistors [25-27,29], organic light-emitting diodes [30], and bulk heterojunction solar cells [31].

For this purpose, we synthesized the phenylterthiophene derivative $(S)-\mathbf{1}$ bearing a chiral side chain and a cyclotetrasiloxane unit at the terminal position of alkyl linker (Figure 1). The synthetic procedure, spectral data, differential scanning calorimetric thermograms, X-ray diffraction patterns and polarizing optical microscopic textures are indicated in the supplementary file (S-1, Scheme S1; S-2, Figures S1-S4). An analogous compound (S)-2 bearing an alkenyl side chain (Figure 1) was 
also synthesized according to the literature reported previously [14]. Compared to alkenyl analog $(S)-2$, the bulky cyclotetrasiloxanering inhibits crystallization; however, it promotes nanosegregation between the $\pi$-conjugated units and the oligosiloxane moieties, resulting in the formation of layer structures $[12,13,32]$. These compounds exhibit an ordered smectic phase at room temperature and ferroelectric chiral smectic $C\left(S^{*} C^{*}\right)$ phase at an elevated temperature. These LC phases are enantiotropic. The mesomorphic properties of chiral LC fluorophenylterthiophene derivatives $(S)-\mathbf{1}$ and $(S)-\mathbf{2}$ are summarized in Table 1 . Recrystallization of compound $(S) \mathbf{- 1}$ from $n$-hexane provides waxy precipitates in the chiral smectic $\mathrm{G}\left(\mathrm{SmG}^{*}\right)$ phase while a crystalline solid is obtained in the recrystallization of compound $(S)-\mathbf{2}$ from $n$-hexane. Compound $(S)-\mathbf{1}$ exhibits higher solubility in various organic solvents as compared with $(S)-2$. The characterization of their mesophases was supported by studies of polarizing optical microscopy (POM), X-ray diffraction and differential scanning calorimetry [12-14].

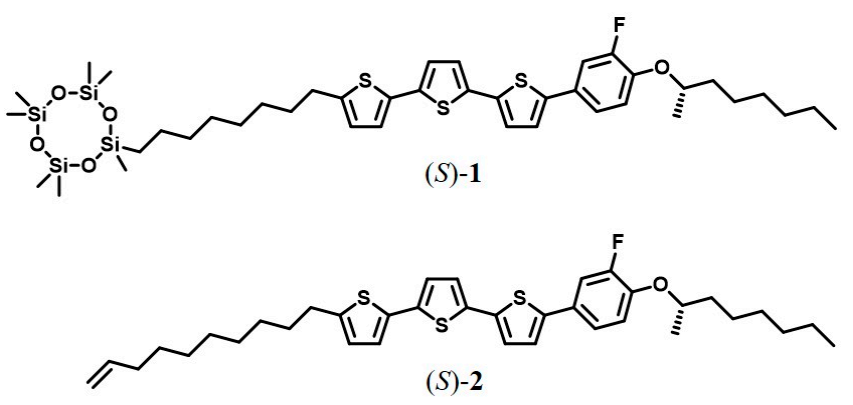

Figure 1. Chemical structures of LC fluorophenylterthiophene derivatives $(S)-\mathbf{1}$ and $(S) \mathbf{- 2}$.

Table 1. Phase transition behaviors LC fluorophenylterthiophene derivatives $(S) \mathbf{- 1}$ and $(S) \mathbf{- 2}$.

\begin{tabular}{cc}
\hline Compounds & $\begin{array}{c}\text { Phase-Transition Temperature } /{ }^{\circ} \mathbf{C} \\
\text { (Enthalpy/kJ Mol } \mathbf{~ M}^{-\mathbf{1}} \text { ) }\end{array}$ \\
\hline$(S)-\mathbf{1}$ & $S m G^{*} 98(14) \mathrm{SmC}^{*} 115(8) \mathrm{Iso}^{\mathrm{a}}$ \\
$(S)-\mathbf{2}$ & $S m G^{*} 125(10) \mathrm{SmC}^{*} 140(9)$ Iso $^{\mathrm{a}, \mathrm{b}}$ \\
\hline
\end{tabular}

a The abbreviations $\mathrm{SmG}^{*}, \mathrm{SmC}^{*}$, and Iso denote chiral smectic $\mathrm{G}$, chiral smectic $\mathrm{C}$, and isotropic liquid phases, respectively. The phase transition temperatures were taken at the peak onset of DSC charts. ${ }^{b}$ Ref. [14].

\subsection{Characterization of Ferroelectricty}

Their ferroelectric properties of the bulk state in the $\mathrm{SmC}^{*}$ phases were evaluated by the Sawyer-Tower method [33]. Samples in the isotropic liquid state were filled by capillary action into ITO sandwich empty cells with a cell gap of $2 \mu \mathrm{m}$ (EHC. Co., Ltd., Tokyo, Japan, KSSO-02/A307P1NSS05). The area of electrodes was $4 \times 4 \mathrm{~mm}$. The temperature of the sample was controlled by a hot stage with a proportional-integral-differential (PID) thermo-controller. Triangular-wave bias $( \pm 25 \mathrm{kV} / \mathrm{cm}, 100 \mathrm{~Hz})$ was applied to the sample cells using a function generator (NF Co., Ltd., Yokohama, Japan, WF1973) and a power amplifier (NF Co., Ltd., Yokohama, Japan, HSA 4011). A current induced by electrical polarization was recorded on a digital oscilloscope (Tektronix, Inc., Salem, MA, USA, TDS 3034C) as the voltage drop across a reference capacitor placed in series with the sample. The capacitance of the reference capacitor is $33 \mathrm{nF}$.

The spontaneous polarization in the bulk and thin-film states was also determined by the polarization inversion method [4], using the same oscilloscope, the same function generator and the same type of samples. Triangular-wave bias was applied to the sample cells. The polarization inversion current was detected by the oscilloscope as a voltage drop through a serial resistor with the resistance of $1 \mathrm{k} \Omega$. Compared to the Sawyer-Tower method, the polarization inversion method is effective for the measurements of FLCs which exhibit a larger leakage current. The detailed estimation of spontaneous polarization values is described in the supplementary files (S-3, S1). 
For the measurement in the thin-film states, we used sandwich-type samples produced by vacuum-deposition of the $\mathrm{Al}$ electrode on the spin-coated thin films of compound (S)-1 with a thickness of around $100 \mathrm{~nm}$ deposited on ITO-coated glass substrates. For the measurement of the spontaneous polarization, the planar alignment of the LC molecules is requisite because the dipole moment of the LC molecules is perpendicular to the molecular axis. The planar alignment was confirmed by POM observations.

\subsection{Preparation of Thin Films of FLCS}

Thin films of compounds (S) $\mathbf{- 1}$ and $(S)-\mathbf{2}$ were deposited on glass substrates by a spin-coating method. The spin-coated thin films were prepared on ITO-coated glass plates under the following conditions (rotational speed: $2000 \mathrm{rpm}$, rotation time: $120 \mathrm{~s}$, concentration of solutions: $20 \mathrm{~g} \mathrm{~L}^{-1}$ in acetone). The surface of the ITO-coated glass plates was hydrophilized by a $\mathrm{UV} / \mathrm{O}_{3}$ method or treated by a friction transfer (FT) technique $[34,35]$. In the FT technique, the substrate was heated to over $200{ }^{\circ} \mathrm{C}$, and the heated surface of the substrate was rubbed with a polytetrafluoroethylene (PTFE) block. PTFE nanofibers adhered on the substrate, aligning parallel to the rubbing direction. The average thickness of prepared LC thin films was around $100 \mathrm{~nm}$.

In situ polymerization of the spin-coated thin films was carried out by the exposure of the thin films on vapors of trifluoromethanesulfonic acid at $70^{\circ} \mathrm{C}$. A spin-coated thin film and a glass container including a few drops of trifluoromethanesulfonic acid were placed in a glass petri dish and it was left at $70{ }^{\circ} \mathrm{C}$ for $30 \mathrm{~min}$. The ring-opening polymerization did not occur below $50^{\circ} \mathrm{C}$, indicating that this in situ polymerization process should require the thermal motion of the cyclotetrasiloxane moieties.

\section{Results and Discussion}

\subsection{Ferroelectricity in the Bulk State of Compound (S) -1}

In the POM observation for the ITO-sandwiched LC cell of (S)-1, broken fan-like textures with stripes originated from helical structures were observed in the $\mathrm{SmC}^{*}$ phase (see the supplementary files; Figure S3a) [35]. The broken fan-like textures indicated that the LC molecules exhibited planar alignment between two ITO electrodes. The helical pitch of $1 \sim 2 \mu \mathrm{m}$ was estimated from the width of stripe patterns in the POM image. On the surface of the bare glass substrate, schlieren textures were observed in the $S m C^{*}$ phase of $(S)-1$. Because the schlieren textures can be observed in a nematic phase as well as $\mathrm{SmC} / \mathrm{SmC}^{*}$ phases with homeotropic alignments, LC molecules of $(S)-\mathbf{1}$ aligned perpendicular to the glass surface [36]. However, this area did not contribute to the electrical measurements. For compound $(S) \mathbf{- 1}$, ferroelectric hysteresis loops were observed in their $S m C^{*}$ phases (Figure 2a). Their spontaneous polarization values were estimated by extrapolation of these polarization curves to zero bias. The spontaneous polarization in the $S m C^{*}$ phase of $(S)-1$ was $35 \mathrm{nC} \mathrm{cm}^{-2}$ at $100{ }^{\circ} \mathrm{C}$, which is smaller than the value of $68 \mathrm{nC} \mathrm{cm}^{-2}$ determined by the Sawyer-Tower method for (S)-2 [14]. A comparable spontaneous polarization, $31 \mathrm{nC} \mathrm{cm}{ }^{-2}$, was obtained by the polarization inversion current measurement, as shown in Figure $2 \mathrm{~b}$. The bulky cyclotetrasiloxane unit of $(S)-\mathbf{1}$ should inhibit the molecular aggregation in the $\mathrm{SmC}^{*}$ phase, resulting in a more disordered structure.

\subsection{Deposition of Thin LC Film}

LC molecules generally align perpendicular to the surface of the substrate in spin-coated films of LC compounds exhibiting smectic phases because the surface energy at the interface between the LC layer and air should strongly influence the molecular alignment [25-27]. Therefore, conventional techniques, such as an alignment layer method using rubbed polyimide thin films could not produce the uniaxially aligned films of LC spin-coated films. We adopted the FT method [33,34] aligning the LC molecules parallel to the surface of the substrate. The interaction of the LC molecules and adhered PTFE nanofibers on the substrates resulted in uniaxial alignment of the LC molecules. This method has been used to align $\pi$-conjugated polymers [37]. 


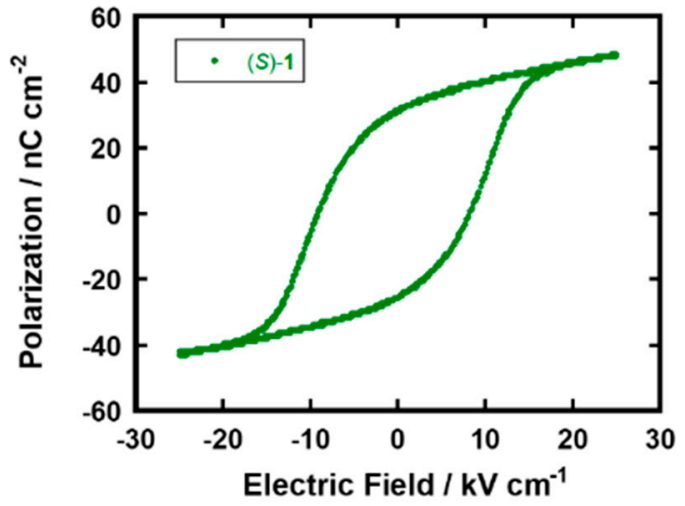

(a)

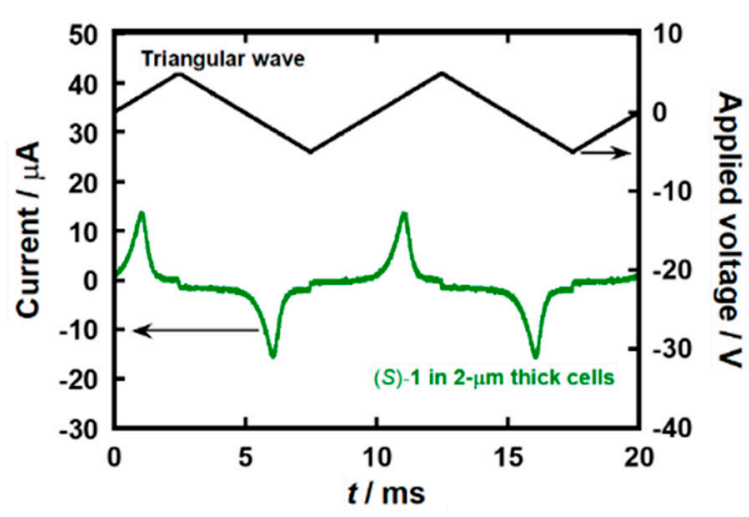

(b)

Figure 2. (a) Ferroelectric hysteresis loop and (b) polarization inversion current in the $\mathrm{SmC}^{*}$ phases of compounds $(S)-\mathbf{1}$ at $100{ }^{\circ} \mathrm{C}$ in $2 \mu \mathrm{m}$ thick cells.

Figure 3 displays polarizing optical micrographs of the spin-coated thin films of compounds $(S) \mathbf{- 1}$ and $(S) \mathbf{- 2}$. For compound $(S) \mathbf{- 2}$, homogeneous thin films were not obtained by the spin-coating method. As shown in Figure 3a, inhomogeneous crystalline films consisting of sub-micron sized crystallites were obtained. The thin films contained many defects and pin holes and the sample for electrical measurements could not be prepared. Because the solubility of compound (S) $\mathbf{2}$ in organic solvents was not so high as that of compound $(S)-\mathbf{1}$, the choice of the solvent was limited in the spin-coating of compound $(S)-2$. In contrast to compound $(S)-2$, homogeneous and continuous thin films could be produced by the spin-coating method for compound $(S)-\mathbf{1}$. It should be noted that the spin-coated thin films of compound $(S)-\mathbf{1}$ were in the $S m G^{*}$ phase at room temperature because compound (S)-1 did not crystallize during the evaporation process of the solvent. In the case of thin films deposited on the $\mathrm{UV} / \mathrm{O}_{3}$-treated ITO surface, polydomain optical textures which consisted of several ten micron-sized birefringent and homeotropic domains were observed in the as-deposited films, as shown in Figure 3b. The molecular orientation in each domain would be random. The LC molecules tended to orient vertical to the substrate surface in the spin-coated films while the LC molecules were aligned parallel to the electrode surfaces (homogeneous alignment) in the $2 \mu \mathrm{m}$-thick LC cell. By the classical rubbing method for an ultrathin polyimide layer deposited on the ITO electrode, homogeneous alignment could not be achieved.
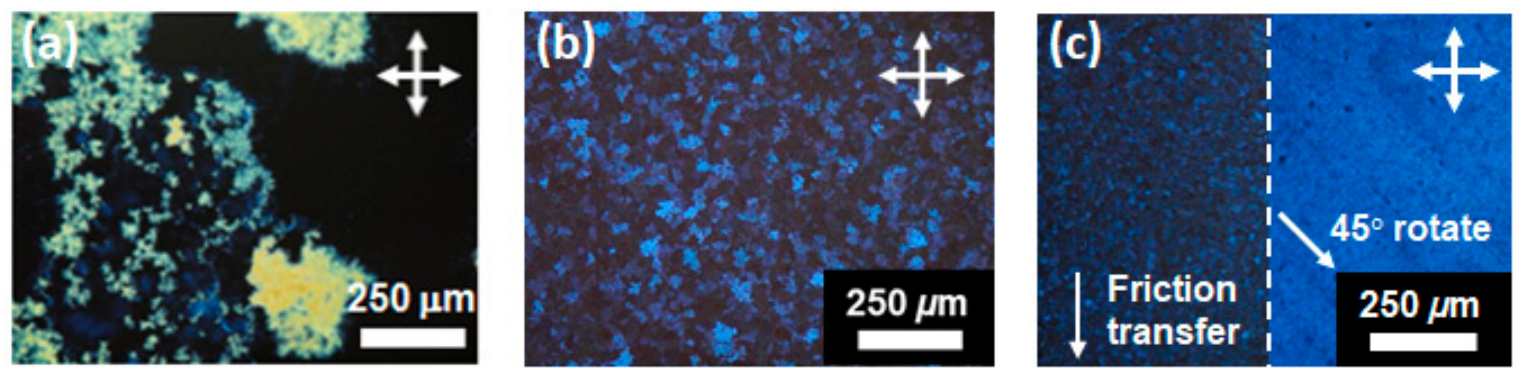

Figure 3. Polarizing optical micrographs of spin-coated thin films at room temperature in $\mathrm{SmG}^{*}$ phases for (a) compound $(S)-\mathbf{2}$ on $\mathrm{UV} / \mathrm{O}_{3}$-treated substrate, (b) compound $(S) \mathbf{- 1}$ on $\mathrm{UV} / \mathrm{O}_{3}$-treated substrate (c) compound (S)-1 on friction-transferred substrate.

On the other hand, uniaxially oriented LC films were obtained using the friction-transferred ITO substrates as shown in Figure 3c. The optical contrast was changed by every 45-degree rotation of samples. The uniaxially extended PTFE fibers adhering on the substrate should strongly restrict the orientation of the LC molecules in the thin films. These optical textures were retained when the sample heated to the temperature range of the $\mathrm{SmC}^{*}$ phase. In the temperature range of the $\mathrm{SmC}^{*}$ phase, 
POM observations revealed only dark field and clear optical textures could not be obtained for both films deposited on $\mathrm{UV} / \mathrm{O}_{3}$-treated and FT-treated substrates because of the small birefringence of the thin films with thicknesses around $100 \mathrm{~nm}$.

\subsection{Ferroelectricity of Thin-film States}

Top Al electrodes were vacuum-deposited on spin-coated films. Ferroelectric polarization of the spin-coated films of compound (S)-1 was evaluated by the Sawyer-Tower method (Al/ LC/ ITO, $\pm 500 \mathrm{kV} \mathrm{cm}^{-1}, 100 \mathrm{~Hz}$ ). Figure 4 a shows hysteresis loops of the spin-coated thin films of $(S)-\mathbf{1}$. The polarization versus electric field curve of the thin film deposited on the UV/O $\mathrm{O}_{3}$-treated ITO surface showed dielectric-like behavior, in which hysteresis was not remarkable, despite the bulk ferroelectricity of compound $(S) \mathbf{- 1}$. In contrast, the thin film prepared on the FT-treated substrate showed ferroelectric hysteresis behavior. The coercive electric field was shifted to around $80 \mathrm{kV} \mathrm{cm}^{-1}$ as compared with $2 \mu \mathrm{m}$-thick LC cell. The shift of coercive electric field could be caused by molecular orientation on the surface and inside of the thin film. The upfield shift could be explained by the surface stabilization effect of FLC molecules. In addition, molecular orientation at the interface between the LC layer and electrodes can also affect the upfield shift. The estimated spontaneous polarization reached around $75 \mathrm{nC} \mathrm{cm}^{-2}$.

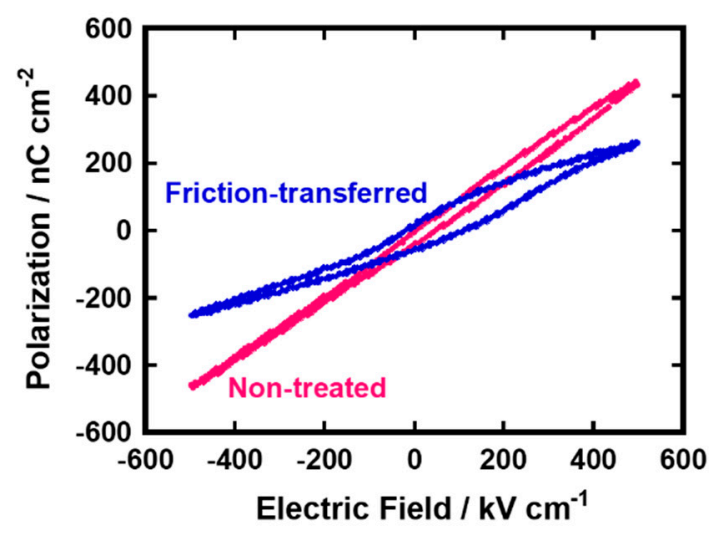

(a)

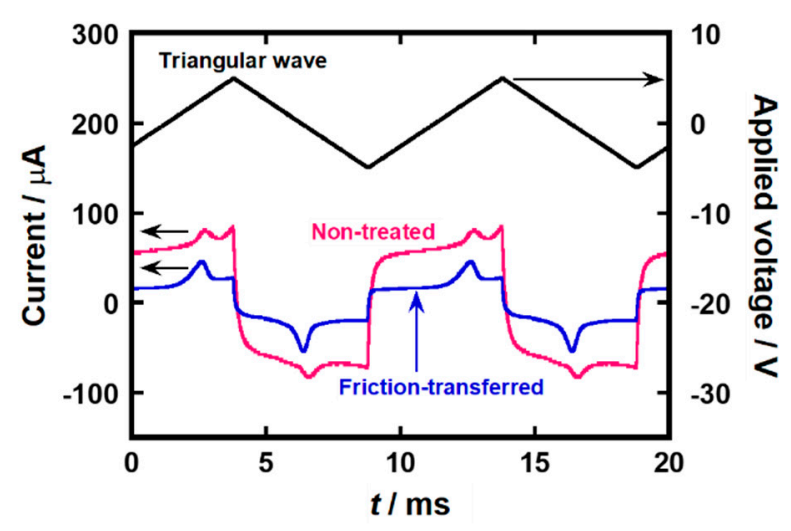

(b)

Figure 4. (a) Hysteresis loops and (b) polarization inversion current under the application of triangular wave for the spin-coated thin film of $(S)-\mathbf{1}$ deposited on non-treated and friction-transferred substrates in the $\mathrm{SmC}^{*}$ phase at $100{ }^{\circ} \mathrm{C}$.

In the samples exhibiting high leakage currents, the polarization values obtained by the Sawyer-Tower method may be overestimated by distortion of hysteresis loops. Therefore, the spontaneous polarizations of the thin films were also measured by the polarization inversion method. Figure $4 \mathrm{~b}$ exhibits the polarization inversion current for the thin films of compound $(S)-\mathbf{1}$ in the $S m C^{*}$ phase at $100{ }^{\circ} \mathrm{C}$. The measurements revealed the spontaneous polarization of $27 \mathrm{nC} \mathrm{cm}$ for a thin film deposited on $\mathrm{UV} / \mathrm{O}_{3}$-treated substrate. For the uniaxially aligned thin film formed by the friction-transfer method, the spontaneous polarization increased to $50 \mathrm{nC} \mathrm{cm}^{-2}$. This value was 1.5 times greater than that in the bulk state of compound (S) $\mathbf{- 1}$.

Small spontaneous polarization and an ambiguous hysteresis loop in the thin films deposited on $\mathrm{UV} / \mathrm{O}_{3}$-treated substrates should originate from the presence of the domains in which the LC molecules were aligned perpendicular to the electrode surface. In the molecules of compound (S)-1, the permanent dipole moments, which contributed mainly to the ferroelectricity, were almost perpendicular to the molecular axis, while the induced dipole moment derived from the polarization of the $\pi$-conjugated unit was parallel to the molecular axis. 
Compared to the spontaneous polarization in the $2 \mu \mathrm{m}$-thick cells, those in the thin-film states on the FT-treated substrates were 1.5 times greater. In past studies on spontaneous polarization measurements of FLC cells with thicknesses larger than $2 \mu \mathrm{m}$, the spontaneous polarization decreased with the decrease in the sample thickness [38-40]. That results have been explained by the confinement of the LC molecules on the substrate surface. In the spin-coated films deposited on FT-treated substrates, the LC molecules are more strongly adsorbed on the electrode surface and the molecular ordering on the electrode surface should induce more ordered structure over the whole thin film. The influence from the molecular orientation on the electrode surface should be more remarkable in the thin-film states in LC cells.

\subsection{In-Situ Polymerization of Thin Films of Compound (S)-1}

Thin films deposited on $\mathrm{UV} / \mathrm{O}_{3}$ - and FT-treated substrates were polymerized by the ring-opening polymerization induced by the vapors of trifluoromethanesulfonic acid. Figure 5 exhibits polarizing optical micrographs of the uniaxially aligned thin films of compound $(S) \mathbf{- 1}$ deposited on $\mathrm{UV} / \mathrm{O}_{3}$-treated substrates before and after the ring-opening polymerization. Birefringent domains with a size of several millimeters were observed, indicating a planar alignment in each domain. There were a few dark domains, although homeotropic alignment could not be confirmed in the domains because of the small size of the domains and low contrast. The sizes and birefringence of LC domains were retained during the ring-opening polymerization induced by the acid vapors. As-deposited thin films were soluble in organic solvents except for alcohol. Polymerized thin films were insoluble in acetone and dichloromethane.
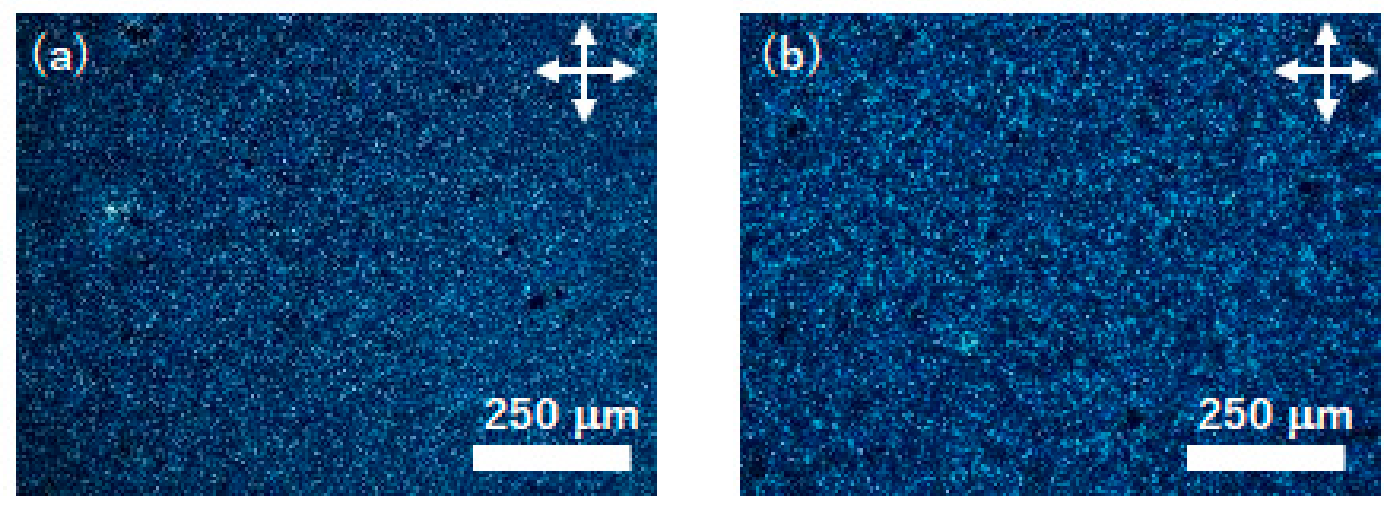

Figure 5. Polarizing optical micrographs of a thin films of compound $(S)-\mathbf{1}$ deposited on $\mathrm{UV} / \mathrm{O}_{3}$-treated substrates (a) before and (b) after the ring-opening polymerization. The polymerization was carried out at $70{ }^{\circ} \mathrm{C}$ and the photographs were taken at $30^{\circ} \mathrm{C}$. White arrows indicate the optical axes of the polarizer and analyzer.

Figure 6 exhibits polarizing optical micrographs of the uniaxially aligned thin films of compound (S)-1 deposited on FT-treated substrates after the ring-opening polymerization. By the polymerization, the thin film was insolubilized in acetone and dichloromethane. As shown in Figure 6, the transmittance of the thin film under a cross-Nicol observation was changed by every 45 -degree the rotation of samples, indicating the uniaxial planar alignment before and after polymerization. The uniaxial alignment of the thin film was retained during the polymerization process. In the polymerized thin films, supramolecular aggregation structures should be immobilized and the micrographic textures did not change when the temperatures of thin films were elevated to $100^{\circ} \mathrm{C}$. 

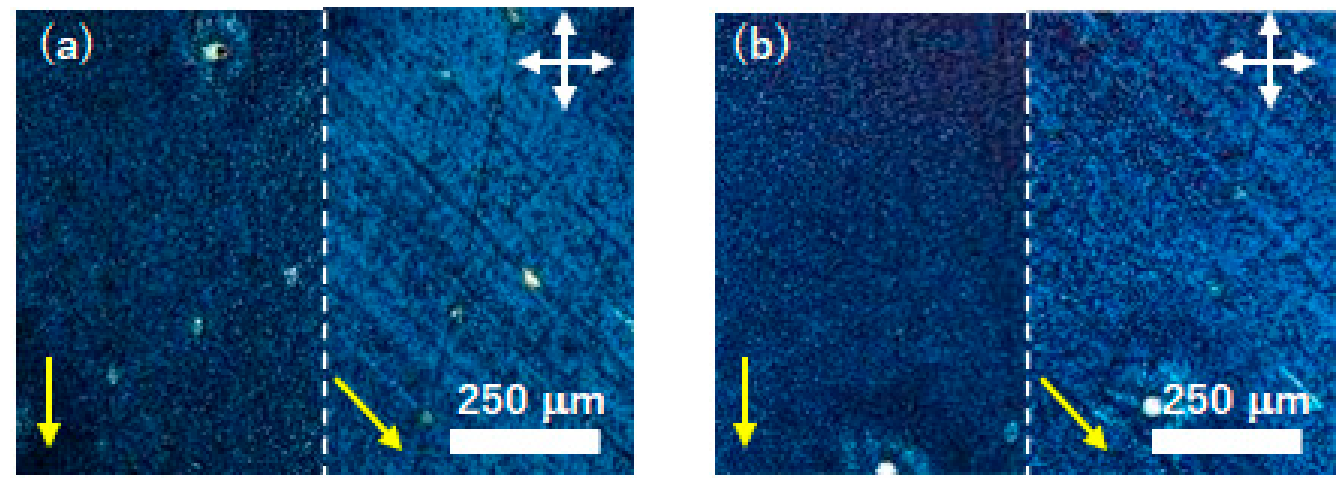

Figure 6. Polarizing optical micrographs of a thin film of compound (S)-1 deposited on FT-treated substrates (a) before and (b) after the ring-opening polymerization. The polymerization was carried out at $70{ }^{\circ} \mathrm{C}$ and the photographs were taken at $30^{\circ} \mathrm{C}$. White arrows indicate the optical axes of the polarizer and analyzer. Yellow arrows denote the direction of the friction in the FT treatment.

\section{Conclusions}

In conclusion, uniaxially aligned spin-coated thin films of $\pi$-conjugated FLC compound (S)-1 bearing a cyclotetrasiloxane moiety were prepared. Compound $(S)-\mathbf{1}$ exhibited $\mathrm{SmC}^{*}$ and $\mathrm{SmG}^{*}$ phases. In the $2 \mu \mathrm{m}$-thick LC cells, the spontaneous polarization value of compound $(S)-1$ was $35 \mathrm{nC} \mathrm{cm}{ }^{-2}$. Compound (S)-1 showed good solubility in acetone $\left(>20 \mathrm{~g} \mathrm{~L}^{-1}\right)$ and other organic solvents, in contrast to the aliphatic analog $(S)-\mathbf{2}$. The spin-coated thin films were prepared on $\mathrm{UV}^{-\mathrm{O}_{3}}$-treated and FT-treated ITO-glass substrates. The uniaxially aligned thin films with a thickness of $100 \mathrm{~nm}$ were deposited on the ITO substrates. The spontaneous polarization was enhanced in the uniaxially aligned thin film and reached $50 \mathrm{nC} \mathrm{cm}^{-2}$. The coercive electric field was upfield shifted due to the surface stabilization of the LC thin layer.

The spin-coated thin films of compound (S)-1 were insolubilized by the ring-opening polymerization induced by the acid vapors. The molecular alignment of the thin films was retained during the polymerization process. Uniaxially aligned thin films of compound $(S)-\mathbf{1}$ could also be polymerized, retaining the uniaxial alignment by this method.

Supplementary Materials: The following are available online at http://www.mdpi.com/2073-4352/10/11/983/s1, Section S-1: Synthetic procedure and spectral data (Scheme S1: Synthetic route of compound (S)-1), Section S-2: Characterization of mesomorphism of (S)-1 (Figure S1: DSC thermogram of compound (S)-1 at the scanning rates of $10 \mathrm{~K} / \mathrm{min}$, Figure S2: X-ray diffraction patterns of compound $(S)-1$ in the (a) SmC* phase at $110{ }^{\circ} \mathrm{C}$, and (b) SmG* phase at $90^{\circ} \mathrm{C}$, Figure S3: Polarizing optical micrographs of compound (S)-1 in the (a) SmC $\mathrm{C}^{*}$ phase at $110^{\circ} \mathrm{C}$, and (b) SmG* phase at $90^{\circ} \mathrm{C}$. The LC samples were filled in an ITO sandwich cell with the gap of $2 \mu \mathrm{m}$, Figure S4: Polarizing optical micrographs of compound $(S)-\mathbf{1}$ in the $S m C^{*}$ phase at $110{ }^{\circ} \mathrm{C}$ under the application of DC bias. The DC voltage was applied (a) to backward direction $(+10 \mathrm{~V})$ and (b) to forward direction $(-10 \mathrm{~V})$. The LC samples were filled in an ITO sandwich cell with the gap of $2 \mu \mathrm{m})$, Section S-3: Evaluation of ferroelectric properties of $(S)-\mathbf{1}$ (Equation. S1: Determination of spontaneous polarization in the polarization inversion current method for (S)-1).

Author Contributions: Conceptualization, M.F.; synthesis, J.N. and A.S.; measurement, J.N. and A.S.; writing-review and editing, M.F. and A.S.; project administration, M.F.; funding acquisition, M.F. All authors have read and agreed to the published version of the manuscript.

Funding: This study was financially supported by a Grant-in-Aid for Scientific Research on Innovative Areas (Element-Block Polymers, No. 15H00753) from the Ministry of Education, Culture, Sports, Science and Technology (MEXT), a Grant-in-Aid for Scientific Research (B) (No. 15H03797) from the Japan Society for the Promotion of Science (JSPS), the TEPCO Memorial Foundation, Ogasawara Toshiaki Memorial Foundation, and the SEI Group CSR Foundation.

Acknowledgments: The authors thank T. Kusunose and T. Ishii at Kagawa University for help with the XRD and DSC measurements, respectively. We also thank A. Sonoda of the National Institute of Advanced Materials Science and Technology for help with NMR spectroscopy for chemical structure identification. We thank H. Moritake of National Defense Academy for fruitful advice for our research.

Conflicts of Interest: The authors declare no conflict of interest. 


\section{References}

1. Clark, N.A.; Lagerwall, S.T. Submicrosecond bistable electro-optic switching in liquid crystals. Appl. Phys. Lett. 1980, 36, 899-901. [CrossRef]

2. Young, C.Y.; Pindak, R.; Clark, N.A.; Meyer, R.B. Light-Scattering Study of Two-Dimensional Molecular-Orientation Fluctuations in a Freely Suspended Ferroelectric Liquid-Crystal. Phys. Rev. Lett. 1978, 40, 773-776. [CrossRef]

3. Lagarwall, J.P.F.; Giesselmann, F. Current Topics in Smectic Liquid Crystal Research. ChemPhysChem 2006, 7, 20-45. [CrossRef]

4. Miyasato, K.; Abe, S.; Takezoe, H.; Fukuda, A.; Kuze, E. Direct Method with Triangular Waves for Measuring Spontaneous Polarization in Ferroelectric Liquid Crystals. Jpn. J. Appl. Phys. 1983, 22, L661-L663. [CrossRef]

5. Funahashi, M. Development of liquid crystalline semiconductors with high carrier mobility and their application to thin-film transistors. Polym. J. 2009, 41, 459-469. [CrossRef]

6. Funahashi, M. Nanostructured Liquid-Crystalline Semiconductors-A New Approach to Soft Matter Electronics. J. Mater. Chem. C 2014, 2, 7451-7459. [CrossRef]

7. Kato, T.; Yoshio, M.; Ichikawa, T.; Soberats, B.; Ohno, H.; Funahashi, M. Transport of ions and electrons in nanostructured liquid crystals. Nat. Rev. Mater. 2017, 2, 17001. [CrossRef]

8. Funahashi, M. Solution-processable electronic and redox-active liquid crystals based on the design of side chains. Flex. Print. Electron. 2020, 5, in press. [CrossRef]

9. Anetai, H.; Wada, Y.; Takeda, T.; Hoshino, N.; Yamamoto, S.; Mitsuishi, M.; Takenobu, T.; Akutagawa, T. Fluorescent Ferroelectrics of Hydrogen-Bonded Pyrene Derivatives. J. Phys. Chem. Lett. 2015, 6, 1813-1818. [CrossRef]

10. Sasaki, T. Photorefractive effect of ferroelectric liquid crystals. Chem. Rec. 2006, 6, 43-51. [CrossRef]

11. Funahashi, M.; Mori, Y. Linearly polarized electroluminescence device in which the polarized plane can be rotated electrically using a chiral liquid crystalline semiconductor. Mater. Chem. Front. 2020, 4, 2137-2148. [CrossRef]

12. Funatsu, Y.; Sonoda, A.; Funahashi, M. Ferroelectric liquid-crystalline semiconductors based on a phenylterthiophene skeleton: Effect of introduction of oligosiloxane moieties and photovoltaic effect. J. Mater. Chem. C 2015, 3, 1982-1993. [CrossRef]

13. Seki, A.; Funahashi, M. Photovoltaic effects in ferroelectric liquid crystals based on phenylterthiophene derivatives. Chem. Lett. 2016, 45, 616-618. [CrossRef]

14. Seki, A.; Funahashi, M. Anomalous photovoltaic effect based on molecular chirality: Influence of enantiomeric purity on the photocurrent response in $\pi$-conjugated ferroelectric liquid crystals. Phys. Chem. Chem. Phys. 2017, 19, 16446-16455. [CrossRef] [PubMed]

15. Seki, A.; Funahashi, M. Chiral photovoltaic effect in an ordered smectic phase of a phenylterthiophene derivative. Org. Electron. 2018, 62, 311-319. [CrossRef]

16. Zhang, C.; Nakano, K.; Nakamura, M.; Araoka, F.; Tajima, K.; Miyajima, D. Noncentrosymmetric Columnar Liquid Crystals with the Bulk Photovoltaic Effect for Organic Photodetectors. J. Am. Chem. Soc. 2020, 142, 3326-3330. [CrossRef]

17. Miyajima, D.; Araoka, F.; Takezoe, H.; Kim, J.; Kato, K.; Takata, M.; Aida, T. Ferroelectric Columnar Liquid Crystal Featuring Confined Polar Groups Within Core-Shell Architecture. Science 2012, 336, $209-213$. [CrossRef]

18. Lehmann, W.; Skupin, H.; Tolksdorf, C.; Gebhard, E.; Zentel, R.; Krüger, P.; Lösche, M.; Kremer, F. Giant lateral electrostriction in ferroelectric liquid-crystalline elastomers. Nature 2001, 410, 447-450. [CrossRef]

19. Yoshino, K.; Uto, S.; Myojin, K.; Nakayama, K.; Kobayashi, K.; Yin, X.H.; Moritake, H.; Ozaki, M. Nonlinear optical properties of ferroelectric liquid crystal. Ferroelectrics 1997, 196, 297-303. [CrossRef]

20. Yoshino, K.; Fuwa, Y.; Nakayama, K.; Uto, S.; Moritake, H.; Ozaki, M. Static and dynamic properties of ferroelectric liquid crystal and their novel applications. Ferroelectrics 1997, 197, 1-9. [CrossRef]

21. Isoda, K.; Matsubara, M.; Ikenaga, A.; Akiyama, Y.; Mutoh, Y. Reversibly/irreversibly stimuli-responsive inks based on N-heteroacene liquids. J. Mater. Chem. C 2019, 7, 14075-14079. [CrossRef]

22. Takenami, K.; Uemura, S.; Funahashi, M. In situ polymerization of liquid-crystalline thin films of electron-transporting perylene tetracarboxylic bisimide bearing cyclotetrasiloxane rings. RSC Adv. 2016, 6, 5474-5484. [CrossRef] 
23. Yu, Y.; Maeda, T.; Mamiya, J.; Ikeda, T. Photomechanical Effects of Ferroelectric Liquid-Crystalline Elastomers Containing Azobenzene Chromophores. Angew. Chem. Int. Ed. 2007, 46, 881-883. [CrossRef]

24. Iino, H.; Hanna, J. Availability of Liquid Crystalline Molecules for Polycrystalline Organic Semiconductor Thin Films. Jpn. J. Appl. Phys. 2006, 45, L867-L870. [CrossRef]

25. Funahashi, M.; Zhang, F.; Tamaoki, N. High Ambipolar Mobility in Highly Ordered Smectic Phase of Dialkylphenylterthiophene Derivative That Can Be Applied to Solution-Processed Organic Field Effect Transistors. Adv. Mater. 2007, 19, 353-358. [CrossRef]

26. Zhang, F.; Funahashi, M.; Tamaoki, N. High-performance thin-film transistors from semiconducting liquid crystalline phases by solution processes. Appl. Phys. Lett. 2007, 91, 063515. [CrossRef]

27. Zhang, F.; Funahashi, M.; Tamaoki, N. Highly mechanically flexible thin film transistors from liquid crystalline semiconductors by solution processing. Org. Electron. 2010, 11, 363-368. [CrossRef]

28. Funahashi, M.; Sonoda, A. High electron mobility in a columnar phase of liquid-crystalline perylene tetracarboxylic bisimide bearing oligosiloxane chains. J. Mater. Chem. 2012, 22, 25190-25197. [CrossRef]

29. Iino, H.; Usui, T.; Hanna, J. Liquid crystals for organic thin-film transistors. Nat. Commun. 2015, 6, 6828. [CrossRef] [PubMed]

30. Aldred, M.P.; Contoret, A.E.A.; Farrar, S.R.; Kelly, S.M.; Mathieson, D.; O’Neill, M.; Tsoi, W.C.; Vlachos, P. A Full-Color Electroluminescent Device and Patterned Photoalignment Using Light-Emitting Liquid Crystals. Adv. Mater. 2005, 17, 1368-1372. [CrossRef]

31. Hori, T.; Miyake, Y.; Yamasaki, N.; Yoshida, H.; Fujii, A.; Shimizu, Y.; Ozaki, M. Solution Processable Organic Solar Cell Based on Bulk Heterojunction Utilizing Phthalocyanine Derivative. Appl. Phys. Exp. 2010, 3, 101602. [CrossRef]

32. Funahashi, M.; Yamaoka, M.; Takenami, K.; Sonoda, A. Liquid-crystalline perylene tetracarboxylic bisimide derivatives bearing cyclotetrasiloxane moieties. J. Mater. Chem. C 2013, 1, 7872-7878. [CrossRef]

33. Pecherskaya, E.A. The use of the Sawyer-Tower method and its modifications to measure the electrical parameters of ferroelectric materials. Meas. Tech. 2007, 50, 1101-1107. [CrossRef]

34. Wittmann, J.C.; Smith, P. Highly oriented thin films of poly(tetrafluoroethylene) as a substrate for oriented growth of materials. Nature 1991, 352, 414-417. [CrossRef]

35. Brunet, M.; Martinot-Lagarde, P. Chiral Smectic C Liquid Crystal, Thick Sample Textures. J. Phys. II 1996, 6, 1687-1725. [CrossRef]

36. Sreenilayam, S.P.; Rodriguez-Lojo, D.; Agra-Kooijman, D.M.; Vij, J.K.; Panov, V.P.; Panov, A.; Fisch, M.R.; Kumar, S.; Stevenson, P.J. de Vries liquid crystals based on a chiral 5-phenylpyrimidine benzoate core with a tri- and tetra-carbosilane backbone. Phys. Rev. Mater. 2018, 2, 025603. [CrossRef]

37. Hosokawa, Y.; Misaki, M.; Yamamoto, S.; Torii, M.; Ishida, K.; Ueda, Y. Molecular orientation and anisotropic carrier mobility in poorly soluble polythiophene thin films. Appl. Phys. Lett. 2012, 100, 203305. [CrossRef]

38. Miyata, H.; Maeda, M.; Suzuki, I. Cell thickness dependence of dielectric properties of ferroelectric liquid crystal (CS-1022). Liq. Cryst. 1996, 20, 303-309. [CrossRef]

39. Roy, S.S.; Majumder, T.P.; Roy, S.K.; Mukherjee, P.K. Effect of spontaneous polarization on smectic C*-smectic $\mathrm{A}^{*}$ phase transition temperature and the thickness dependence of the spontaneous polarization of ferroelectric liquid crystal. Liq. Cryst. 1998, 25, 59-62. [CrossRef]

40. Patel, J.S.; Goodby, J.W. The dependence of the magnitude of the spontaneous polarization on the cell thickness in ferroelectric liquid crystals. Chem. Phys. Lett. 1987, 137, 91-95. [CrossRef]

Publisher's Note: MDPI stays neutral with regard to jurisdictional claims in published maps and institutional affiliations.

(C) 2020 by the authors. Licensee MDPI, Basel, Switzerland. This article is an open access article distributed under the terms and conditions of the Creative Commons Attribution (CC BY) license (http://creativecommons.org/licenses/by/4.0/). 